\title{
Emotion and Concentration Integrated System: Applied to the Detection and Analysis of Consumer Preference
}

\author{
Wei-Yen Hsu \\ National Chung Cheng \\ University \\ shenswy@gmail.com
}

\author{
Jun-Yi Lu \\ National Chung Cheng \\ University \\ alex42132000@hotmail.com
}

\author{
Chih-Chia Chien \\ National Chung Cheng \\ University \\ owo2dog8@yahoo.com.tw
}

\author{
Meng-Chiu Hsieh \\ National Chung Cheng University \\ mengchiu36@gmail.com
}

\author{
Yu-Hsiang Wang \\ National Chung Cheng University \\ thumbg92626@hotmail.com.tw
}

\begin{abstract}
With the expansion of consumer market, the appearance becomes an important issue when consumers make decisions under the situation of similar qualities and contents. Accordingly, to attract consumers, companies cost and take much attention on product appearance. Compared to using questionnaires individually, obtaining humans' thoughts directly from their brains can accurately grasp the actual preference of consumers, which can provide effective and precious decisions for companies.

In this study, consumers' brainwaves which are related to concentration and emotion are extracted by wearing a portable and wireless Electroencephalography (EEG) device. The extracted EEG data are then trained by using perceptron learning algorithm (PLA) to make the judgments of concentration and emotion work well with each subject. They are then applied to the detection and analysis of consumer preference. Finally, the questionnaires are also performed and used as the reference on training process. They are integrated with brainwaves data to create one prediction model which can improve the accuracy significantly. The Partial Least Squares is used to compare the correlation between different factors in the model, to ensure the test can accurately meet consumers' thoughts.
\end{abstract}

Keywords: brainwave; consumer preference; Electroencephalography $(E E G) ; \quad$ concentration; emotion; training; perceptron learning algorithm (PLA)

\section{Introduction}

Making products stand out in the market and catch consumers' attentions is a key factor to increase profits for companies, and become a storm to sweep the consumer market.

There is a recognition that product design is emerging as a key marketing element [1-3]. The visual appearance of a product plays a significant role in determining responses of consumers [4] and is recognized as an opportunity for differential advantage in the market place [5].

In our daily lives, there are many factors affecting consumers' selections before purchasing. The various aspects of product design play a vital role in the interaction between consumer and product and thus may affect consumer preference [6]. The response from respondents can reflect that the consumer preference will be affected by the appearance of packaging during their buying process. Therefore, Packaging is crucial because it is able to create emotional attachment in consumers' minds during their first glimpses [7]. Generally, enterprises will use questionnaire or telephone to investigate consumer preference, and use the statistical data of selling to help managers make strategies. But there is a difference between interview and actual buying action because the emotion at interview may be different from looking at the physical product. Invalid or bad results of a questionnaire may cause the decision makers to make the wrong decision [8].

The goal of the research is to accurately grasp the preference of product appearance. For example, in consumer behavior, when there are different products with same prices and consistent features, consumers may choose according to the appearances of products. Sometimes consumers 
cannot make decisions by themselves. It is generally accepted that the look of a product or its package has an important effect on consumer choice at the point of purchase [9]. In the situation of consumers not considering prices or functions, product appearance plays the most important role. Garber's (1995) model emphasizes the effects of product appearance on consumer attention [10]. It also makes it more difficult to establish a reference, because there is no way of knowing what consumers' preferences are. In the case of unpredictable preference, it is important to know how to let companies get more powerful evaluation criteria for them to design and build the direction of product appearance. We want to find a way to achieve this goal, so we try to build this system, to detect brainwaves, to help make further analysis in consumer preference [11].

To efficiently and accurately understand the emotional reactions and degrees of concentration of consumers when they are making response, we use a brain-computer interface device to collect the consumers' brainwaves. It generates EEG data to help analyzing and discussing the corresponding relationships between mood swings and the replied answers [12]. Depending on the different correspondences, companies can make different marketing strategies to make product sales achieve maximum benefits. Comparing with those complex and inconvenient brainwave devices which are time-consuming and uncomfortable to wear, the device we adopt can be more quickly and efficiently test every subject. In addition, the system is executed on computer, so it can be performed anytime and anywhere with our easy and accurate brainwave device. The computer system quickly generates analyzing results, and quickly gives reference data of the testing.

In this research, we focus on the use of electroencephalogram to detect and integrate subjects' concentration degrees with emotion changes. With a series of training process, we use incremental steps to assess consumers' reactions when they are answering different questions, and quickly judge the result of preference degree. In the future, we expect to use our system to precisely detect the preference of products from consumers and contribute the data to support company to build the direction of appearance design. It does not only reduce the risk of release of a new product design, but also catches consumers' eyes more precisely.

\section{Theoretical background}

\subsection{Brainwave}

In human brains, numerous neurons communicate with each other. The action potential which is generated after activation is transmitted to the synapse (Synapse) via axons (Axon). [13] The release of neurotransmitters can cause the next neuron to generate postsynaptic potentials, which further stimulate the neuron to generate action potentials. Brainwave intensity under normal circumstances is $100 \mathrm{uV}$ less, and usually only dozens of $\mathrm{uV}$. The frequency ranges from $0.1 \mathrm{~Hz}$ to $40 \mathrm{~Hz}$. It can be applied in the detection of depth of sleep, mental status and mentation.

\subsection{Electroencephalography (EEG)}

EEG is typically a non-invasive (however invasive electrodes are often used in specific applications) method to record electrical activity of the brain along the scalp. EEG measures voltage fluctuations resulting from ionic current within the neurons of the brain. In clinical contexts, EEG refers to the recording of the brain's spontaneous electrical activity over a period of time, as recorded from multiple electrodes placed on the scalp. Diagnostic applications generally focus on the spectral content of EEG, that is, the type of neural oscillations that can be observed in EEG signals [14].

\subsection{Emotiv EPOC}

The Emotiv EPOC is a high resolution, neurosignal acquisition, processing wireless headset that monitors 16 channels of EEG data. EPOC internally samples at a frequency of $2048 \mathrm{~Hz}$, which then gets down-sampled to $128 \mathrm{~Hz}$ sampling frequency per channel, and sends the data to a computer via Bluetooth.

It utilizes a proprietary USB dongle to communicate using the $2.4 \mathrm{GHz}$ band. Prior to use, all felt pads on top of the sensors have to be moistened with a saline solution.

The Emotiv Software Development Kit (SDK) provides a packet count functionality to ensure no data is lost, a writable marker trace to ease single trial segmentation tasks, and real-time sensor contact display to ensure quality of measurements.

The effectiveness of the EPOC headset as a real-time brain EEG scanner was demonstrated in a number of recent publications [15].

\subsection{Emotion influence decisions}


Because of the emotional impact of brainwave is determined by many factors, of which the most important are Alpha $(\alpha)$ waves, Theta $(\theta)$ waves and Gamma $(\gamma)$. Studies have shown that in the case of the good mood, Alpha $(\alpha)$ waves will show a positive correlation; Theta $(\theta)$ waves are used as the basis of subjects determining shapes and colors [16]. The literature of the marketing points out that when we observe pleasant or unpleasant advertisings, it will increase Theta $(\theta)$ waves and Alpha $(\alpha)$ waves activity asymmetry respectively in the right and left hemispheres [17].

People in positive emotion will tend to maintain the status and make use of general knowledge in the past and rule of thumb to process messages resiliently. However, when people in a negative mood state, they will tend to change the status quo to change the negative mood of the moment and do more logical and careful thinking to deal with the messages. Emotion is also seen to influence decisions [18].

\subsection{Concentration influence decisions}

Alpha $(\alpha)$ waves and Theta $(\theta)$ waves are the factors that influence the mindfulness. Alpha $(\alpha)$ waves are the excitation of the mindfulness state and Theta $(\theta)$ waves maintain the mindfulness state [19-20].

A psychological research shows that "mindfulness" is a finite resource. Also, mindfulness doesn't just work when sitting in stillness. It's also a fantastic tool for making key decisions, including high speed, "on the fly" decisions [19]. Mindfulness can help you filter out mental chatter, weigh your options objectively, tune into your intuition and ultimately make a decision that you can stand behind completely [20].

When we force ourselves to focus on doing something, we will start to consume energy of mindfulness. With more and more things that need to be handled, there are less and less energy reserves. Less energy means the ability to deal with things will be lower. This phenomenon is called "mental depletion". In other words, because the focus force is limited, every day the transactions we are able to handle are limited.

According to the study [21], a judge has to deal with a number of cases in one day, so the judge's decision will be influenced by "non-legal factors". When the judge's mindfulness is exhausted, he will tend to avoid the complex decision-making, back to the safer "default" mode.

\subsection{Partial least squares}

Partial least squares (PLS) regression is a popular method for soft modeling in industrial applications [22]. PLS regression is a method for constructing predictive models when the factors are many and highly collinear. Note that the emphasis is on predicting the responses and not necessarily on trying to understand the underlying relationship between the variables.

For example, PLS is not usually appropriate for screening out factors that have a negligible effect on the response. However, when prediction is the goal and there is no practical need to limit the number of measured factors, PLS can be a useful tool.

If the number of factors gets too large (for example, greater than the number of observations), you are likely to get a model which fits the sampled data perfectly but that will fail to predict new data well. This phenomenon is called over-fitting. In such cases, although there are many manifest factors, there may be only a few underlying or latent factors that account for most of the variation in the response. The general idea of PLS is trying to extract these latent factors, accounting for as much of the manifest factor variation 1 as possible while modeling the responses well. For this reason, the acronym PLS has also been taken to mean "projection to latent structure". It should be noted, however, that the term "latent" does not have the same technical meaning in the context of PLS as it does for other multivariate techniques. In particular, PLS does not yield consistent estimates of what are called "latent variables" in formal structural equation modeling.

\subsection{Consumer behavior}

The study of consumer behavior is about the processes that consumers use to choose and dispose of products and services. The deeper definition of it will also include how that process impacts the world. Consumer behavior incorporates ideas from several sciences including psychology, biology, chemistry and economics [23].

"All marketing decisions are based on assumptions and knowledge of consumer behavior."[24]. Researching consumer behavior is a complex process, but understanding consumer behavior is critical for companies.

Consumer behavior attempts to understand the decision-making processes of buyers, both individually and in groups, such as how emotion affects buying behavior. It studies characteristics of 
individual consumers such as demographics and behavioral variables in an attempt to understand people's demands. It also tries to assess influences on the consumers from groups such as family, friends, sports, reference groups, and society in general [25].

\subsection{Perceptron Learning Algorithm (PLA)}

PLA is developed by Frank Rosenblatt in 1957. This algorithm is used in machine learning which focuses on the case of binary classifier [26]. The algorithm will initial the weight to random number and decide an input which represents numbers into one group or the other by vector $\mathrm{W}=\mathrm{W}+\mathrm{y} * \mathrm{X} \mid$. When the input does not belong to the right class, the vector will be adjusted and make every input conform their class exactly. The formula applied in our system is $\mathrm{h}(\mathrm{x})=\operatorname{sign}(\mathrm{w} 0+\mathrm{w} 1 *$ concentration + $\mathrm{w} 2$ *emotion). By learning from the system, we divide concentration and emotion into two areas, and find the best vector $\mathrm{W}$ in our experiment.

\section{Method}

\subsection{Capturing brainwaves}

The goal we want to achieve is to grasp the consumer preference accurately. Hence, we develop this system by using the brain-computer interface which knows the effects of consumers' emotion and degrees of concentration. To know the consumer preference on appearances of products, we ask for some subjects to extract their brainwaves as internal brainwave data and use questionnaires to get their external options. In our experiment, we focus on using the comparison between internal brainwave data and external option to find the best weight to calculate the preference value and use it to find the preference interval for the actual test in the future.

Each experiment needs ten to fifteen minutes. At first, we will let them wear EEG, and detect their brainwaves by these 16 channels. After the contact quality of each sensor is good (represented by a color code), we can gain the $\operatorname{Alpha}(\alpha), \operatorname{Beta}(\beta)$, $\operatorname{Theta}(\theta)$ and $\operatorname{Gamma}(\gamma)$ from brainwaves and store them into database for the following comparison and analysis. In next step, we use discrete wavelet transform to gain the wave bands we want.

\subsection{Discrete wavelet transform}

It Discrete wavelet transform is used to divide a continuous time function into several wavelets.
Using discrete wavelet transform can build a timefrequency signal with well localized time domain and frequency domain. Through the algorithm of filters, we can find the needed wave brands gradually. The methods are shown below:

$\mathrm{x}[\mathrm{n}]$ : Discrete inputted signal, the length is $\mathrm{N}$.

$\mathrm{g}[\mathrm{n}]$ : It is a low pass filter, which can filter the high frequencies of inputted signals and output low frequencies.

$\mathrm{h}[\mathrm{n}]$ : It is a high pass filter, which is opposite to the low pass filter. It can filter the low frequencies of inputted signals and output high frequencies.

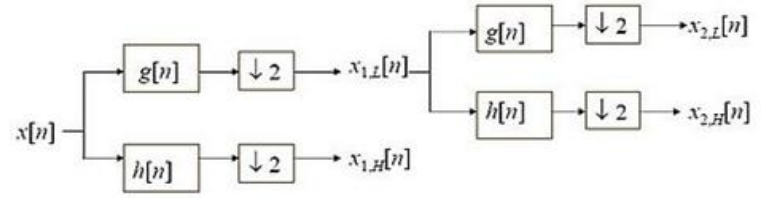

\subsection{Design an experiment}

We find 50 subjects to conduct the experiment. Because people have the different sensitive degrees of brainwaves, these 50 fixed subjects will become the decision makers in the future actual test after training their brainwave data. Hence, we need to extract their brainwave data to do training and machine learning, so the computer can improve the data quality when every time subjects do the test again. The subjects need to do 50 times of test at the beginning. Each test lasts for 40 seconds. We will combine external options by using questionnaire of subjects with brainwaves data, and detect signal stability of brainwaves at the same time. At the first 10 seconds, the system will filter out the instability brainwaves. The system will select two pictures randomly to be a group after the experiment starts. The pictures are drawn just by black line, because the reference of our test is using shapes. It is because we want to reduce other variables in order to focus on the brainwave detecting. Each picture runs for 20 seconds. The system will grasp each four brainwave values of concentration and emotion every second, totally each 80 values. It detects the validity of each value and records them into the result table for us to calculate the mean of each brainwave value of concentration and emotion. In the test, the system will record the brainwaves of concentration and brainwaves of emotion, making them to be the factors and supposing concentration will influence the development of emotion. Hence, we build a 
model of experiment process. Figure 1 is the structural model of test.

According to different ages and genders, we will find 50 subjects: 25 men and 25 women. It is because companies aim different consumer segmentation of age to promote their products. We will divide the subjects into segments based on age. Each group has five men and five women and the age difference between each group is ten-year.

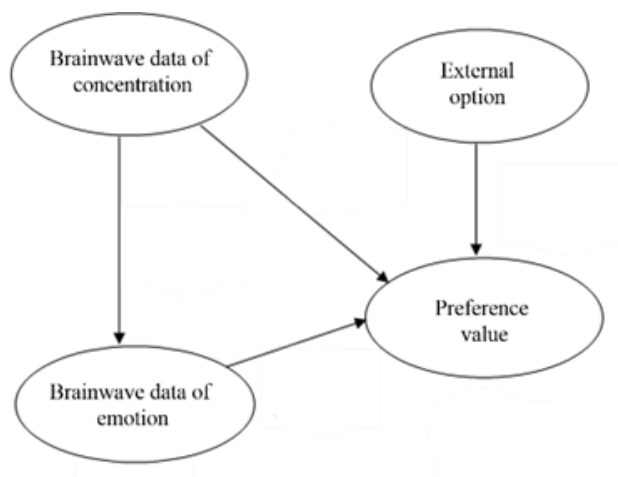

\section{Figure 1. Structural model of experiment}

\subsection{Determine an interval of preference}

At first, in order to get the best weight to find the interval of preference, we use PLA to integrate brainwaves of concentration with brainwaves of emotion to do the training. The function is $\mathrm{h}(\mathrm{x})=$ $\operatorname{sign}(\mathrm{w} 0+\mathrm{w} 1 *$ concentration $+\mathrm{w} 2 *$ emotion $)$. Every subject has his own learning h(x). Every time when one subject input the new brainwave data of concentration and brainwave data of emotion, the computer will put dot (concentration, emotion) into subject's coordinate of preference value and compare with the external option which came from the previous questionnaire. In this coordinate, normal vector $\mathrm{W}$ will be divided into two areas, one is "like" and the other is "dislike". If this dot is out of the right area, computer will adjust the normal vector $\mathrm{W}=\mathrm{W}+\mathrm{y} * \mathrm{X} \mid$ and change the weight of concentration and emotion. Using this function can let the system improve the quality of data and learn by itself. Hence, we can get the different interval of preference of each subject.

According to our previous model of experimental architecture, we use PLS to estimate the brainwaves of concentration, brainwaves of emotion and external options to access the significance between each other.
The system uses EMOTIV EPOC \& EMOTIVE EEG to get users' brainwave signals. It also puts the needed brainwave data into the database to be the standard that used to determine people's preference degree. The system architecture is shown in Figure 2.

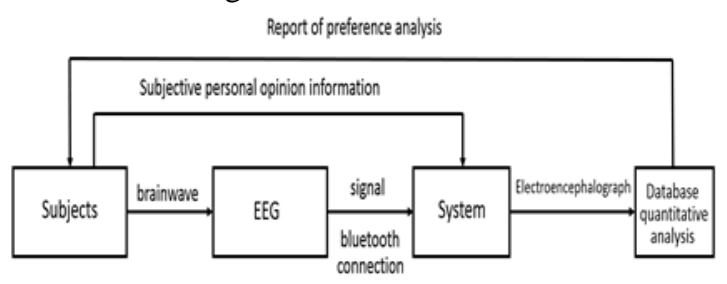

Figures2. System architecture

\section{Result}

According to the value from the system and options we collect from the experiment, we aggregate the data In the table of results, we can divide two parts. First one is the report table including the processed data of brainwaves and external options of subjects. The external options in the table show the chosen result of subjects. We use external options to be the input reference of machine learning for helping the system do training and get the best weight to find the interval of preference. Second is the correlation between different factors on the model. We want to find a preference interval from brainwave data by repeatedly testing. According to the external options and find each subject's preference degree for the actual test of products.

\section{Table 1.Part result of brainwave and questionnaire}

\subsection{System architecture}




\begin{tabular}{|c|c|c|c|c|c|}
\hline \multirow[b]{2}{*}{ Subject } & \multirow[b]{2}{*}{ picture } & \multirow[b]{2}{*}{$\begin{array}{l}\text { Valid } \\
\text { value }\end{array}$} & \multicolumn{2}{|c|}{ Brainwave value (average) } & \multirow[b]{2}{*}{$\begin{array}{l}\text { Externa } \\
\text { options }\end{array}$} \\
\hline & & & concentration & $\begin{array}{l}\text { Emotion } \\
\text { (excite.) }\end{array}$ & \\
\hline \multirow[t]{2}{*}{1} & A1 & 65 & 0.8932517 & 0.4950338 & \\
\hline & A2 & 53 & 0.7944321 & 0.501458 & chosen \\
\hline \multirow[t]{2}{*}{2} & A1 & 62 & 0.8040042 & 0.4202442 & chosen \\
\hline & A2 & 78 & 0.8861949 & 0.4293434 & \\
\hline \multirow[t]{2}{*}{3} & A1 & 45 & 0.5581248 & 0.5247778 & \\
\hline & A2 & 61 & 0.7634656 & 0.4922924 & chosen \\
\hline \multirow[t]{2}{*}{4} & Al & 67 & 0.8800727 & 0.4507176 & chosen \\
\hline & A2 & 58 & 0.8627813 & 0.3865770 & \\
\hline \multirow[t]{2}{*}{5} & A1 & 33 & 0.5745802 & 0.6934524 & chosen \\
\hline & A2 & 65 & 0.881354 & 0.4802543 & \\
\hline \multirow[t]{2}{*}{6} & A1 & 24 & 0.8969509 & 0.8070259 & \\
\hline & A2 & 42 & 0.5978001 & 0.883521 & chosen \\
\hline \multirow[t]{2}{*}{7} & A1 & 61 & 0.590323 & 0.4860513 & chosen \\
\hline & A2 & 55 & 0.5617179 & 0.5944557 & \\
\hline \multirow[t]{2}{*}{8} & A1 & 54 & 0.6601946 & 0.4959034 & chosen \\
\hline & A2 & 71 & 0.7740469 & 0.5325213 & \\
\hline \multirow[t]{2}{*}{9} & A1 & 51 & 0.6200864 & 0.6853133 & \\
\hline & A2 & 74 & 0.7299225 & 0.596738 & chosen \\
\hline \multirow[t]{2}{*}{10} & A1 & 59 & 0.745967 & 0.5614825 & \\
\hline & A2 & 39 & 0.8005445 & 0.6626107 & chosen \\
\hline \multirow[t]{2}{*}{11} & A1 & 68 & 0.8613247 & 0.4740505 & chosen \\
\hline & A2 & 54 & 0.9305649 & 0.4590027 & \\
\hline
\end{tabular}

\subsection{Correlation analysis of model}

We design a model to research the preference correlation. In this structure of experiment, we use a progressive step to detect the thoughts of subjects. We consider that when subjects are looking at the appearance of a product or a mark, they must decide one with different objects. For example, color, shape or pattern. So we focus on the shape, using a group of pictures to test. There are two pictures in one group. We think that concentrations will influence emotion. In addition, we also think the external options and brainwaves data might influence the preference value which is calculated by the function. Therefore, we use PLS analysis to analyze the correlation between every step of the structure. The result of PLS analysis is shown in the Figure 2. The R2 values indicate that the amount of variances that dependent variables are explained by independent variables.

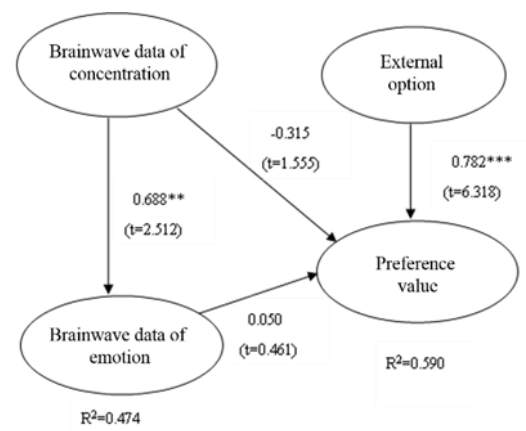

Figure 3. PLS result: Result ${ }^{*} P<0.05,{ }^{* *} P<0.01,{ }^{* \star *} P<0.001$

The total sample we used is 50. From the model, we can find that the $\mathrm{R} 2$ value of brainwave data of emotion is 0.474 , meaning that brainwave data of concentration explains more than 45 percent of variance in brainwave data of emotion, proving that emotion is influenced by concentration significantly. The R2 value of internal and preference value is 0.590 , meaning that other variables explain almost 60 percent of variance inpreference value. It represents that the external options will significantly affect the internal and preference value.

The average variance extracted values (AVEs), are three of all above recommended threshold of 0.5 [27]. The result is shown in Table 2. Table 2 has AVE and correlation coefficient of each variable. Three squares of root are higher than the correlations among the measures. In conclusion, it indicates that the model can almost conform to the data.

\section{Table 2. Correlation, and average variance extracted}

\begin{tabular}{|l|l|l|l|l|l|}
\hline AVE/Correlation & & & & & \\
\hline Latent Construct & AVE & $(1)$ & $(2)$ & $(3)$ & $(4)$ \\
\hline (1)Brainwave data of concentration & 0.529 & 0.727 & & & \\
\hline (2)Brainwave data of emotion & 0.580 & 0.688 & 0.762 & & \\
\hline (3)External option & 0.500 & -0.120 & -0.087 & 0.707 & \\
\hline (4)Preference value & 0.335 & 0.243 & 0.157 & 0.707 & 0.596 \\
\hline
\end{tabular}

\subsection{Actual test}

In this step, we will let enterprises test their products in their target market by our fifty subjects. This test will be based on the standard which we studied upon. In this test, the subjects only need to put on the device and watch the pictures to do the simple test. At the same time, the data will be saved in database and be calculated. Simultaneously, the 
system will use this new data to improve the quality of data. The output "preference value" can determine the final preference degree. Using this method, the extensive testing can be easier. For different consumer groups, we can get the different information as references. After testing, the new strategy or decision can be made on the basis of the reports. Now we do several times of actual test. To verify our system which precisely grasps the consumer preference, we find more than 900 samples to test their preference in each actual test and compare with the result of actual test from the fifty subjects.

\subsection{Commodity decision}

After finding the subjects according to the enterprise strategy of the different target market and the test is done, the system will give the results of these different pictures. Then the report with different statistic charts comes out. The report should include the different consumer groups' results and see which kind of products has the most consumers' highest preference value in the target market. With the report, the enterprise can have one more reference when they need to make the better decision, or launch some different kinds of products for different target markets.

\section{Discussion}

Our study shows that the concentration situation of a subject can let us know his or her degree of preference. When someone is fond of a thing, he or she must be concentrating on this thing. We can assert that emotion will be influenced by concentration and it will help determine the consumer preference in product design. Therefore, we build model and use PLS to prove the correctness of our assertion. This is a very important key for a company to know consumers' emotion of several designs and make the correct decisions to attract consumers. The design of a product might affect someone's reactions deeply, so a company has to watch carefully on the design. In this study, we can see subjects' degree of preference on different objects and colors. This kind of difference can help a factory, a seller, or a company to understand consumers' preferences and decide what kind of shapes and colors should be designed to be sold.

When we go to a market or a store to shop, we do not always choose the product that we certainly feel good or really be fond of. Sometimes we just think that this product might be my favorite thing but actually not like it very much. This condition will not make consumers come back to buy this product again. The perfect design on a product can make consumers keep an eye on it, so this is a useful way to make them keep buying the products they have produced.

Actually, when we test the subjects we can find many interesting facts. A man chose and circled the first design but in his mind, this man actually had more excitement on the second design. In contrast, someone thought the first design was the prettiest and the data shows that he really thought as the same as what he chose. These two conditions are very different to each other. The first condition shows the person's answer is different with his mind, it means the external degree of preference is different with the internal degree of preference. The other shows that the person's mind is similar to his answer, that is, the external degree is consistent with the internal degree. Therefore, we hope to use EMOTIV EPOC \& EMOTIV EEG to compare the internal and external degree of preference to understand the subjects.

\subsection{Implications for research}

We believe this system can bring more benefits to a company. A company always does not have any idea of what consumers like and doesn't know how to design a product that will attract more consumers to come back to the store to consume it again. A company usually wastes a lot of time on surveying consumers.

What companies do now to know consumers' minds is bringing questionnaires to people on the street or in the stores to ask them some questions. For example, there might be two or three different products show on the questionnaire paper to make people choose their favorite products. Companies believe deeply that this way can help them get the answers they want. They think it is a good way for their companies to produce products that can allure these consumers. Sometimes, this is not a reliable way to understand consumers. What they choose are not always as the same as what they really like.

The purpose of our research is to detect people's degrees of preference and help companies to actually provide consumers' needs. It is very crucial for companies because they can make the right decisions as soon as they realize consumers' thoughts. When the products fascinate consumers very well, the possibilities of consumers who turn heads will increase very rapidly. 
In our research, we can find out that someone chooses the first design, and the data shows that he or she actually likes the other one than the one he chooses. This is useful information for companies to compare the traditional questionnaire method with the new method that uses EMOTIV EPOC \& EMOTIV EEG. The traditional questionnaire method will not realize the true emotion of people. But with the new method by using EMOTIV EPOC \& EMOTIV EEG, we can know what subjects answer and also what they are really thinking about it. That can be a new opportunity for companies to understand consumer preference.

\subsection{Implications for practice}

Our results show that knowing consumer preference is a crucial part of a company to make products or designs that can perfectly surprise consumer and prompt them to buy the products. We have several implications.

The first implication is that those useful data can let us know a lot of helpful information about a person's emotion. Not only what things they like but also the things they dislike. A company has to avoid designing products that would be disagreeable or would disturb the public [28]. The emotion helps realize a lot of details.

The second implication is that companies need to concern more about their consumers. However, companies need to clearly know what their consumers like and make some strategies by guessing their thoughts rather than making the decision by themselves. Consumers' preference changes rapidly, it represents that targeting the expectation of consumers is significant. Without wasting time and losing accuracy using traditional investigation, our system can provide quick time of concern and precise reference of strategies for companies. These concerns can help us do machine learning and adjust our weight of concentration and emotion brainwave data to help system learn by itself, so that companies can get more precise and high quality data again and again. In the word, consumers' emotion plays an important role in a company's decision making. Only understanding consumers can make companies capture consumers' hearts. A proper management of consumer behavior is a strong competitive advantage for the companies [29].

\subsection{Limitations and future directions}

Although this study helps a lot in decision making and analyzing consumer preference, there might be some factors that affect subjects' thoughts, so it causes that we can't detect the deeper emotion of the subjects. This might not be that correct when there are too many factors influencing someone.

Therefore, we have some directions we want to do in the future research. To reduce the factors which will affect the detection of brainwave data, we want to make a strict standard of experiment, such as the environment of the experiment and living habits of subjects, ensuring the experiment will not be disturbed by the external factors and consumers will not be influenced by their mental states. The second direction is that we want to make the analysis between consumer preference and consumer segmentation, such as age or gender. We want to find the related rules between these two variables, expecting to provide more business insights for companies. The third direction is that we make an actual test after finishing the system. Now we test four times, but we want to increase to more than 10 times to prove the effect of our system more certainly.

\section{Conclusion}

This study provides a function to detect the inside thought of the people. Combining the concentration and emotion brainwave data to increase the accuracy of the product preference. We use computer learning and training skill to automatically improve the quality of data, ensuring the actual performance of product survey can precisely make the decision. Besides, we use the PLS analysis method to discuss the relation between the concentration and emotion, proving that concentration will influence the emotion and deeply change the decision of the product preference. Based on our detecting function, company can more clearly to meet the expectation of consumer.

After finishing the building of system and repeatedly training the data, we make a verified actual test for knowing the goal we achieve. At result, four times of test all reach our goal and the result from subjects of actual test conforms to the results of our fifty subjects, proving that our system can grasp the consumer preference precisely by a series of trainings from the fifty subjects' brainwave data. The contribution of our system can provide business a novel and a different function to investigate the consumers and support a precise 
reference to make the strategies on their appearance design.

\section{References}

[1] P. Kotler and G Alexander Rath, "Design: A powerful but neglected strategic tool", Journal of business strategy, 5, 2, 1984, pp. 16-21.

[2] M.B. Holbrook and R.B. Zirlin, "Artistic creation, artworks, and aesthetic appreciation: Some philosophical contributions to nonprofit marketing", Advances in nonprofit marketing, 1, 1, 1985, pp. 1-54.

[3] M. Wallendorf, "The formation of aesthetic criteria through social structures and social institutions", Advances in consumer research, 7, 1, 1980, pp. 3-6.

[4] N. Crilly, J. Ltrie, and P.J. Clarkson, "Seeing things: consumer response to the visual domain in product design”, Design studies, 25, 6, 2004, pp. 547-577.

[5] M.E. Creusen and J. P. Schoorman, "The different roles of product appearance in consumer choice", Journal of product innovation management, 22, 1, 2005, pp. 6381.

[6] W. Robert and Jr. Veryzer, "The Place of Product Design and Aesthetics in Consumer Research", Advances in Consumer Research, 22, 1995, pp. 641-645.

[7] Z.T. Harith., et al. "Coffee packaging: Consumer perception on appearance, branding and pricing", International Food Research Journal, 21, 3, 2014, pp. 849-853.

[8] D. Ergu and G. Kou, "Questionnaire design improvement and missing item scores estimation for rapid and efficient decision making", Annals of Operations Research, 197, 1, 2012, pp. 5-23.

[9] L.L. Garber, "The Package Appearance in Choice." Advances in Consumer Research, 22, 1995, pp. 653-660.

[10] J.P. Schoorman and H.S. Robben, "The effect of new package design on product attention, categorization and evaluation", Journal of Economic Psychology, 18, 2, 1997, pp. 271-287.

[11] K.S. CHEN and S.J. HE, "Application of brainwave instrument research in various fields", Taiwan Academic Network Conference, 2013, pp. 1011-1016.

[12] T.W. Tsai and W.L. Shih, "Using brain wave measuring instruments analysis of visual images of emotional recognition", Conference of Taiwan Institute of Kansei, 2013.

[13] Lodish H, Berk A, Zipursky SL, Molecular Cell Biology. $4^{\text {th }}$ edition, 2000

[14] L. F. Nicolas-Alonso and J. Gomez-Gil, "Brain computer interfaces A review", Sensors, 12, 2, 2012, pp. 1211-1279.

[15] R. N. Khushaba , C. Wise , S Kodagoda , J Louviere , B. E. Kahn, and C. Townsend, Consumer neuroscience: Assessing the brain response to marketing stimuli using electroencephalogram (EEG) and eye tracking, 40, 9, pp.3803-3812, 2013.

[16] M.C.M. Bastiaansen, R. Oostenveld, O. Jensen, and P. Hagoort, "I see what you mean: theta power increases are involved in the retrieval of lexical semantic information", Brain Lang, 106, 1, 2008, pp.15-28.
[17] G. Vecchiato, J. Toppi, L. Astolfi, F. D. V.Fallani, F. Cincotti,D. Mattia, F. Bez, and F. Babiloni, "Spectral EEG frontal asymmetries correlate with the experienced pleasantness of TV commercial advertisements", Med Biol Eng Comput, 49, 5, 2011, pp.579-583.

[18] N. Schwarz and G. Clore, "Feelings and phenomenal experiences. In E. T. Higgins \& A. W. Kruglanski (Eds.)", Social Psychology: Handbook of Basic Principles, 1996, pp. 433- 465.

[19] W. Klimesch,"EEG-alpha rhythms and memory processes", International Journal of Psychophysiology, 26, 1-3,1997, pp 319-340

[20] M. Doppelmayra, T. Finkenzellerb,P. Sausenga, "Frontal midline theta in the pre-shot phase of rifle shooting: Differences between experts and novices", 46, 5, 2008, pp 1463-1467

[21] How to use mindfulness to make key decision Available from: https://siyli.org/2013/08/

[22] C. Gregoire, 10 Things Highly Intuitive People Do Differently, 2015, Available from: http://www.huffingtonpost.com/2014/03/19/the-habits-ofhighly-intu_n_4958778.html

[23] Shai Danzigera, Jonathan Levavb \& Liora AvnaimPesso, "Extraneous Factors in Judicial Decisions", PROCEEDINGS OF THE NATIONAL ACADEMY OF SCIENCES 6889, 108, 17, 2011.

[24] Randall D. Tobias. "An Introduction to Partial Least Squares Regression", SAS Institute Inc., Cary, NC

[25] Kuester and Sabine (2012), "MKT 301: Strategic Marketing \& Marketing in Specific Industry Contexts", University of Mannheim, p. 110.

[26] Del I. Hawkins, David L. Mothersbaugh, Roger J. Best (2007), "Consumer Behavior: Building Marketing Strategy"

[27] Elizabeth A. Minton, Lynn R. Khale (2014), "Belief Systems, Religion, and Behavioral Economics", New York: Business Expert Press LLC.

[28] Freund, Y. Schapire, R. E, "Large margin classification using the perceptron algorithm", Machine Learning, 37, 3, pp. 277-296

[29] D. Barclay, R. Thompson, and C. Higgins, "The partial least squares (PLS) approach to causal modeling: Personal computer adoption and use an illustration", Technology Studies, 2, 2, 2015, pp. 285-309.

[30] George Ad"r, Victor Adr" and N.E. Pascu , Logo Design and the Corporate Identity, Procedia-Social and Behavioral Sciences, 51,2012, pp. 650-654.

[31] M.A. Revilla-Camacho, M. Vega-Vázquez1, and F. José Cossío-Silva, "Customer participation and citizenship behavior effects on turnover intention", Journal of Business Research, 68, 2015, pp. 1607-1611. [32] M.C.CHEN, A.L.CHIU, and H.H. CHANG, "Mining changes in customer behavior in retail marketing." Expert Systems with Applications, 28, 4, 2005, pp. 773-781.

[33] A. Porcelli and M. Delgado, "Acute stress modulates risk taking in financial decision making", Psychological Science, 20, 3, 2009, pp.278.

[34] Shai Danzigera, Jonathan Levavb \& Liora AvnaimPesso, "Extraneous Factors in Judicial Decisions", 
PROCEEDINGS OF THE NATIONAL ACADEMY OF SCIENCES 6889, 108, 17, 2011.

[35] J. Wong and C. Yeh, "Tourist hesitation in destination decision making", Annals of Tourism Research, 36, 1, 2009, pp. 6-23.

[36] F. Rosenblatt, The Perceptron--a perceiving and recognizing automaton. Report 85-460-1, Cornell Aeronautical Laboratory, 1957.

[37] S. Chena, J. Liua, H. Wanga, and J.C. Augustob, "A group decision making model for partially ordered preference under uncertainty", Information Fusion, 25, 2015, pp. 32-41.

[38] N. Nishino, T. Takenaka, H. Koshiba, and K. Kodama, "Customer preference based optimization in selecting product/service variety", CIRP Annals Manufacturing Technology, 63, 1, 2014, pp. 421-424.

[39] R. Attri and S. Grove, "Application of preference selection index method for decision making over the design stage of production system life cycle", Journal of

[44] G.Garcia-molina, T.TSONEVA, and A.Nijholt, "Emotional brain-computer interfaces", International journal of autonomous and adaptive communications systems, 6, 1, 2013, pp.9-25.

[45] R.Horlings, D.Datcu, and L.J.Rothkrantz, "Emotion recognition using brain activity." In: Proceedings of the 9th international conference on computer systems and technologies and workshop for PhD students in computing, 2008, pp. 6.

[46] T. Costa, E. Rognoni, and D. Galati, "EEG phase synchronization during emotional response to positive and negative film stimuli", Neuroscience Letters, 406, 2006, pp. $159-164$.

[47] Rami N. Khushaba,Chelsea Wise,Sarath Kodagoda , Jordan Louviere,Barbara E. Kahn,Claudia Townsend, "Consumer neuroscience: Assessing the brain response to marketing stimuli using electroencephalogram (EEG) and eye tracking", Expert Systems with Applications, 40, 9, 2013, pp. 3803-3812. [48] P. Bobrov, A. Frolov, C. Cantor, I. Fedulova, M. Bakhnyan, A. Zhavoronkov, "Brain-Computer Interface Based on Generation of Visual Images",PLoS ONE 6(6): e20674. doi: 10.1371/journal.pone.0020674

[49] S.P. Kellya and R.G. O'Connell, "The neural processes underlying perceptual decision making in humans: Recent progress and future directions", Journal of Physiology-Paris, 109, 1, 2015, pp. 27-37.

[50] I. Nunes, S. Miles, M. Luck, S. Barbosa, amd C. Lucena, "Decision making with natural language based preferences and psychology-inspired heuristics", Engineering Applications of Artificial Intelligence, 42, 2015, pp. 16-35.

[51] J.S. Lerner, D.A. Small, and G. Loewenstein, "Heart strings and purse strings", Psychological Science, 15, 5, 2004, pp. 337-341.
King Saud University - Engineering Sciences, 27, 2, 2015, pp. 207-216.

[40] A. Yousfia, A.K. Dey, R. Saidi, and J.H. Hong, "Introducing decision-aware business processes", Computers in Industry, 70, 2015, pp. 13-22.

[41] J.R. McColl-Kennedy, P. G. Patterson, A. K. Smith, and M. K. Brady, "Customer Rage Episodes: Emotion, Expressions and Behaviors", Journal of Retailing, 85, 2, 2009, pp. 222-237.

[42] A. Floh and M. Madlberger, "The role of atmospheric cues in online impulse-buying behavior", Electronic Commerce Research and Applications, 12, 6, 2013, pp. 425-439.

[43] K. Crowley, A. Sliney, I. Pitt,and D.Murphy, "Evaluating a brain-computer interface to categorise human emotional response." In: 2010 10th IEEE International Conference on Advanced Learning Technologies, 2010, pp. 276-278. 